\title{
COMUNICAÇÃO
}

\section{FEBRE MACULOSA NO MUNICIPIO DE PEDREIRA - ESTADO DE SÃO PAULO - BRASIL. - RELAÇÃO ENTRE OCORRÊNCIA DE CASOS E PARASTTISMO HUMANO POR IXODÍDEOS}

\author{
Virgilia Luna Castor de Lima, Ana Cristina Figueiredo, Marta Gislene \\ Pignatti e Mauricio Modolo
}

\begin{abstract}
A febre maculosa foi identificada no Estado de São Paulo e Minas Gerais na primeira metade deste século ${ }^{38914}$.

No Estado de São Paulo não há um registro sistemático de casos desta enfermidade. Travassos $^{14}$ em publicação do ano de 1945 apresenta dois mapas mostrando a distribuição provável da transmissão no estádo àquela época. A área registrada é extensa, no entanto, o autor não refere a fonte de seus dados nem os discute no texto do artigo, o qual centra sua atenção em questões técnicas sobre a obtenção de uma vacina.
\end{abstract}

Após esta publicação o que se dispõe, em termos de casuística da febre maculosa no estado são os registros de casos internados no hospital estadual especializado em doenças infecciosas e parasitárias, o "Instituto de Infectologia Emílio Ribas". Foram diagnosticados, neste hospital, 53 casos da doença, no período de 1957 a $1974^{13}$ e 10 casos de 1976 a $1982^{10}$. A maioria deles foram procedentes de áreas rurais de municípios vizinhos da capital tais como Mogi das Cruzes, Diadema e Santo André.

Em 1985 foram identificados casos suspeitos de febre maculosa na zona rural do município de Pedreira, situado na região administrativa de Campinas, a $90 \mathrm{~km}$ a noroeste da capital do Estado (longitude 46 ${ }^{\circ} 54^{\prime 2} 27^{\prime \prime}$, latitude 22044'21”). Este município estava incluído no mapa da publicação de 1945 , citada acima, além de outros situados nas suas proximidades, como local de transmissão da doença, no entanto, não se tinha nos serviços

\footnotetext{
Superintendência de Controle de Endemias - SUCEN, Regional Campinas, São Paulo, SP.

Endereço para correspondência: Dra. Virgília Luna Castor de Lima. SUCEN, SR5. Rua São Carlos 546, 13035-420 Campinas, SP, Brasil.

Recebido para publicação em 16/08/94.
}

de saúde da área nenhum registro da doença nas últimas décadas.

No período de 1985 a 1988 foram registrados neste município onze casos supeitos da doença tendo quatro evoluido para óbito. Entre os suspeitos, quatro tiveram confirmação através de reação de imunofluorescência indireta.

Praticamente todos os casos da doença surgiram no segundo semestre do ano predominando nos meses de setembro $e$ outubro, a semelhança do que foi observado em Minas Gerais4.

A maioria dos casos suspeitos e confirmados eram provenientes de duas localidades rurais situadas a aproximadamente $5 \mathrm{~km}$ da cidade de Pedreira na direção do município de Jaguariúna.

Encontraram-se, amplamente distribuidos no município, carrapatos da espécie Amblyomma cajennense, responsável pela transmissão da febre maculosa no Brasil.

Como medidas de controle da transmissão da doença, foram priorizadas as atividades educativas, tanto voltadas para a população sob risco como para os profissionais de saúde pois as ações que visam a diminuição do carrapato vetor são pouco efetivas ${ }^{11}$.

Para respaldar os trabalhos educativos realizou-se na área um inquérito pelos visitadores sanitários da SUCEN, através de visitas domiciliares com o objetivo de conhecer a variação sazonal do parasitismo humano por ixodídeos implicados na transmissão da doença. Por ocasião da visita era solicitada a informação dos moradores sobre se haviam sido parasitados por carrapato nos últimos 30 dias. Eram entrevistadas as pessoas presentes na casa naquele momento e solicitadas informações sobre os ausentes. Em seguida as pessoas e animais da casa eram examinados para verificação da presença de 
Comunicação. Lima VLC, Figueiredo AC, Pignatti MG, Modolo M. Febre maculosa no município de Pedreira, Estado de São Paulo, Brasil. Relação entre ocorrência de casos e parasitismo bumano por ixodideos. Revista da Sociedade Brasileira de Medicina Tropical 28:135-137, abr-jun, 1995.

parasitas. Em caso positivo coletavam-se os espécimens que eram levados para identificação em laboratório. Solicitava-se ainda aos moradores que guardassem os carrapatos, caso tivessem sido parasitados no intervalo entre uma visita e outra, para serem recolhidos na próxima visita e identificados.

Junto com estas atividades eram também passadas orientações sobre a prevenção da doença, sintomas e local onde procurar atendimento no caso de haver suspeita da enfermidade. $O$ estudo foi iniciado em abril de 1987 tendo-se feito visitas domiciliares nos seguintes meses deste ano: abril, junho, agosto, outubro e novembro. Continuou-se o estudo no ano seguinte, visitando-se as casas nos meses de janeiro, abril, maio, junho, julho, agosto, outubro, novembro e dezembro.

Nestes meses foram visitadas as 31 casas de uma das localidades e $20 \%$ das 200 casas da outra localidade. As casas desta última foram numeradas e eram selecionadas através de sorteio.

Foram realizadas durante o período estudado 3338 entrevistas. Deste total constatou-se parasitismo, ou foi referido parasitismo nos últimos 30 dias, em 304 entrevistas o que corresponde a $9,10 \%$ do total.

O que se observou foi que, coincidindo com o período de aparecimento dos casos, ocorreu um aumento da proporção de pessoas parasitadas, ou que referiram parasitismo, entre as investigadas, a partir do mês de agosto, tendo se apresentado um pico rnáximo no mês de outubro, nos dois anos estudados (Figura 1).

A explicação para a predominância de casos nesta época seria a de que no período que vai do final do inverno ao início do verão predominam as formas mais maduras do $A$. cajennense que podem dar uma maior percentagem de picadas infectantes ${ }^{41232}$. Tudo indica que há provavelmente uma geração deste ixodídeo por ano ${ }^{5}$ e apesar de serem encontrados seus três estádios em qualquer mês ocorrem picos bem definidos de cada estádio em determinados meses. Existe ainda uma preferência das ninfas e dos carrapatos adultos para infectarem animais de médio $e$ grande porte enquanto que a larvas infectam preferencialmente animais de pequeno porte ${ }^{6}$.

No que diz respeito à identificação dos carrapatos coletados durante o estudo, houve

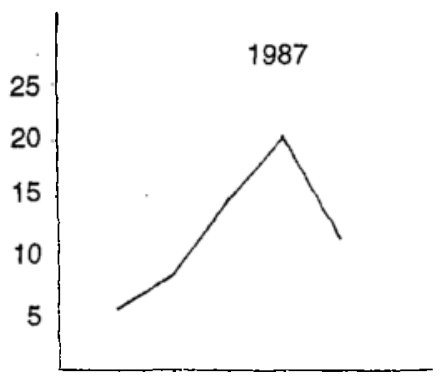

Abr Jun Ago Out Nov

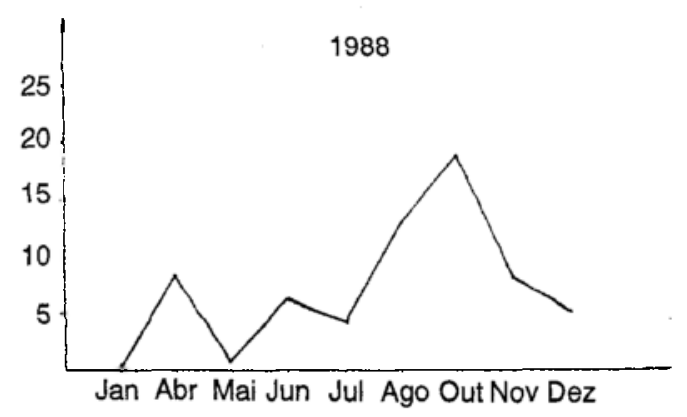

Figura 1 - Porcentagem de moradores parasitados nas localidades estudadas - Pedreira, 1987-1988.

uma predominância da espécie $A$. cajennense ao lado do $R$. sanguineus $(55,9 \%$ e $38,9 \%$ respectivamente). Apesar do A. cajennense ser a espécie mais encontrada parasitando a população humana ela foi, também, encontrada de maneira importante no cão e no cavalo, o que chama a atenção para a possibilidade de participação destes animais no transporte deste vetor para os ambientes próximos ao homem 3 .

Continuam ocorrendo casos da doença no município, inclusive óbitos decorrentes de diagnóstico tardio, havendo ainda suspeita de transmissão em municípios vizinhos, como por exemplo Jaguariuna.

Registra-se a necessidade de se estabelecer um programa oficial de Vigilância da febre maculosa no município de Pedreira e municípios vizinhos. Sendo importante lembrar que os Estados Unidos, no início da década de 70 apresentaram um aumento no número de casos em várias regiões, decorrente em grande parte da implantação, pelo Centro te Controle de Doenças, de um programa de vigilância da "Rock Mountain Spotted Fever". 
Comunicação. Lima VLC, Figueiredo AC, Pignatti MG, Modolo M. Febre maculosa no município de Pedreira, Estado de São Paulo, Brasil. Relação entre ocorrência de casos e parasitismo bumano por ixodideos. Revista da Sociedade Brasileira de Medicina Tropical 28:135-137, abr-jun, 1995.

Para o sucesso no controle dessa enfermidade é fundamental a orientação dos serviços de saúde para a suspeita e diagnóstico precoces dos casos como também da população, no sentido da prevenção do parasitismo, da pesquisa e retirada de carrapatos em curto espaço de tempo, quando da exposição a áreas infestadas e, por fim, da procura de atendimento médico quando apresentar os primeiros sintomas.

Dentro désta perspectiva cabe, para finalizar, também lembrar que o carrapato é vetor de mais tres infecções, a "doença de Lyme", a "febre recorrente" e a "encefalite por arbovirus".

\section{AGRADECIMENTOS}

Agradecimentos póstumos ao Prof. Dr. Domingos Baggio pela disponibilidade e dedicação em dar orientações e discutir as dúvidas.

\section{REFERÊNCIAS BIBLIOGRÁFICAS}

1. Burgdorfer W, Adkins TR, Priester LE. Rocky Mountain Spotted Fever (Tick-Borne Typhus) in South Carolina: An educational Program and tick/rickettsial survey in 1973 and 1974. The American Journal of Tropical Medicine and Hygiene 24: 866-872, 1975.

2. Campbell CC, Hobbs JHJ, Marranghello L, Vargas M, Shepard C, Feldman RA.An apparent outbreak of rickettsial ilness in Costa Rica, 1974. Bulletin of the Pan American Health Organization 12:104$110,1978$.

3. Dias E, Martins AV. Spotted Fever in Brasil - A summary. The American Journal of Tropical Medicine and Hygiene 19: 103-108, 1939.

4. Galvão MAM. A Febre Maculosa Brasileira em Minas Gerais e seus determinantes. Tese de Mestrado, Escola Nacional de Saúde Pública, Rio de Janeiro, RJ, 1988.
5. Guglielmone AA, Margold AJ, Aguirre DH, Gaido AB. Ecological Aspects of Four Species of Ticks found on Cattle in Salta, Northw est Argentina. Veterinary Parasitology 35:93-101,1990.

6. McDade JE, Newhouse VF. Natural History of Rickettsia ricketsii. Annual Review of Microbiology 40: 287-309, 1986.

7. MMWR Editorial Note. Rickettsioses. Weekly Epidemiological Records 30:234-235, 1986.

8. Monteiro JL.A vaccinação preventiva como base da prophylaxia do "Typho Exanthemático de São Paulo (Rickettisiose neotropica) Memórias do Instituto Butantã 10:1-16, 1935-1936.

9. Piza JT. Considerações epidemiológicas e clínicas sobre o Tifo Exantemático de São Paulo. In: Piza JT, Meyer JR, Salles GL (eds) Tifo Exantemático de São Paulo. Sociedade Impressora Paulista, São Paulo p. 11-119, 1932.

10. Rosenthal C. Riquetsioses. In:Amato Neto V (ed) Doenças Transmissíveis. Savier, 3a edição, São Paulo p. 737-750, 1989.

11. Serra Freire NM. Epidemiologia de Amblyomma cajennense: Ocorrência Estacional e Comportamento dos Estádios Não-Parasitários em Pastagens do Estado do Rio de Janeiro. Arquivos da Universidade Federal Rural do Rio de Janeiro, Itaguai, 5:187-193, 1982.

12. Taylor PJ, Tanner WB, Rawlings JA, Buck J, Elliot LB, Dewlett HJ, Taylor 1), Betz TG. Sorological Evidence of Subclinical Rocky Mountain Spotted Fever Infections in Texas. The Journal of infectious diseases 151:367-369, 1985.

13. Tiriba AC, Monteiro EV. Riquetsioses. In: Veronesi R (ed) Doenças Infecciosas e Parasitárias $7^{2}$ edição, Guanabara Koogan,Rio de Janeiro p 213226, 1985.

14. Travassos J, Vallejo-Freire A. Criação Artificial de Amblyoma cajennense para o Preparo da Vacina contra a Febre Maculosa. Memórias do Instituto Butantã 18:145-235, 1944-1945. 